\title{
Microcircuits for Night Vision in Mouse Retina
}

\author{
Yoshihiko Tsukamoto, ${ }^{1}$ Katsuko Morigiwa, ${ }^{2}$ Mika Ueda, ${ }^{1}$ and Peter Sterling ${ }^{3}$ \\ ${ }^{1}$ Department of Biology, Hyogo College of Medicine, Nishinomiya, Hyogo 663-8501, Japan, ${ }^{2}$ Department of Physiology \\ and Biosignalling, Graduate School of Medicine, Osaka University, Suita, Osaka 565-0871, Japan, and ${ }^{3}$ Department of \\ Neuroscience, University of Pennsylvania, Philadelphia, Pennsylvania 19104
}

Because the mouse retina has become an important model system, we have begun to identify its specific neuron types and their synaptic connections. Here, based on electron micrographs of serial sections, we report that the wild-type mouse retina expresses the standard rod pathways known in other mammals: (1) rod $\rightarrow$ cone (via gap junctions) to inject rod signals into the cone bipolar circuit; and (2) rod $\rightarrow$ rod bipolar $\rightarrow$ All amacrine $\rightarrow$ cone bipolar $\rightarrow$ ganglion cell. The mouse also expresses another rod circuit: a bipolar cell with cone input also receives rod input at symmetrical contacts that express ionotropic glutamate receptors (Hack et al., 1999, 2001). We show that this rod-cone bipolar cell sends an axon to the outer (OFF) strata of the inner plexiform layer to form ribbon synapses with ganglion and amacrine cells. This rod-cone bipolar cell receives direct contacts from only $20 \%$ of all rod terminals. However, we also found that rod terminals form gap junctions with each other and thus establish partial syncytia that could pool rod signals for direct chemical transmission to the OFF bipolar cell. This third rod pathway probably explains the rod responses that persist in OFF ganglion cells after the well known rod pathways are blocked (Soucy et al., 1998).

Key words: mouse retina; microcircuitry; rod circuits; bipolar cells; gap junctions; electron microscopy
Until recently, the anatomical connections of mammalian photoreceptors seemed well understood. Cones and rods were known to form chemical synapses on separate classes of bipolar cell (for review, see Vaney et al., 1991; Sterling, 1998; Boycott and Wässle, 1999; Sharpe and Stockman, 1999). Cone bipolar cells synapse directly on ganglion cells and serve high-light levels (daylight), whereas rod bipolar cells connect to ganglion cells only indirectly via an interneuron and serve low-light levels (starlight). Rods were also known to form electrical synapses with cones and thus to obtain indirect access to the cone bipolar circuits under medium-light levels (twilight). These parallel circuits, identified and quantified in cat (Kolb and Famiglietti, 1974; Kolb, 1977; Sterling et al., 1988), rabbit (Strettoi et al., 1990; Young and Vaney, 1991), and primate (Mills and Massey, 1995), have been considered fundamental to the mammalian design and different from the design in fish in which rods and cones form chemical synapses on the same bipolar cells (Stell et al., 1977; Ishida et al., 1980).

However, recordings from mouse ganglion cells now suggest a direct pathway from rods to cone bipolar cells (Soucy et al., 1998). In a mouse retina genetically modified to be "coneless," a fast rod signal was observed in OFF ganglion cells. Clearly, the signal could not reach cone bipolar cells via the known pathway (rodcone coupling), so the most likely pathway in this retina would be for the rod to synapse directly onto dendrites of an OFF cone bipolar cell. The normal mouse showed responses with nearly identical kinetics, suggesting that this pathway might be a basic

Received May 22, 2001; revised July 23, 2001; accepted Aug. 15, 2001.

This work was supported by Japan Society for the Promotion of Science Grantin-Aid 12878144 (Y.T.) and National Institutes of Health Grant EY 00828 (P.S.). We thank Noga Vardi and Robert Smith for suggestions to this manuscript and Sharron Fina for preparing it.

Correspondence should be addressed to Yoshihiko Tsukamoto, Department of Biology, Hyogo College of Medicine, 1-1, Mukogawa, Nishimomiya, Hyogo 6638501, Japan. E-mail: ytsuka@hyo-med.ac.jp.

Copyright (C) 2001 Society for Neuroscience $\quad 0270-6474 / 01 / 218616-08 \$ 15.00 / 0$ feature of mouse retina. Subsequently, contacts were identified from rods to processes that express ionotropic glutamate receptors (iGluRs) (Hack et al., 1999, 2001) and thus are strong candidates for the second-order neurons of this pathway.

To search for this predicted pathway, as well as other basic circuits, we prepared electron micrographs of serial sections through retinas of wild-type mice. Reconstructing from this material, we identified the standard mammalian circuits for night vision but also a type of OFF cone bipolar cell that collects from rods as well as cones. This confirms the prediction of a direct pathway from rods to OFF bipolar cells. Only $20 \%$ of rods directly contact this bipolar cell, but signals from the remaining rods might reach it via rod-rod gap junctions observed here and previously unknown in mammals.

\section{MATERIALS AND METHODS}

Animals and tissue preparation. Retinas were obtained from two mice: mouse 1, C57BL/6J, 9 weeks old, female, 20 gm (SLC, Shizuoka, Japan); mouse 2 , hybrid of $129 / \mathrm{SvJ} \times \mathrm{C} 57 \mathrm{BL} / 6 \mathrm{~J}$, 94 weeks old, female, $38 \mathrm{gm}$ (129/SvJ; The Jackson Laboratory, Bar Harbor, ME). All experiments were conducted in compliance with the institutional and NIH guidelines for animal care and treatment. After deep anesthesia with sodium pentobarbital $(45 \mathrm{mg} / \mathrm{kg}$, i.p.), mouse 1 was perfused with a mixture of $2 \%$ paraformaldehyde, $2.5 \%$ glutaraldehyde, and $1 \%$ acrolein in phosphate buffer $(0.1 \mathrm{M}), \mathrm{pH}$ 7.4. Excised pieces of the posterior retina were immersed in the same fixative with $1 \%$ tannic acid replacing acrolein, microwave irradiated for $10 \mathrm{~min}$, and left at room temperature for $3 \mathrm{hr}$. Tissue was post-fixed with $1 \%$ osmium tetroxide for $2 \mathrm{hr}$. Mouse 2 was perfused with $4 \%$ paraformaldehyde in cacodylate buffer $(0.1 \mathrm{M}), \mathrm{pH} 7.4$. Pieces of the posterior retina were immersed in $2 \%$ paraformaldehyde, $3 \%$ glutaraldehyde, and $2 \mathrm{~mm}$ calcium chloride in cacodylate. After microwave irradiation, tissue remained in the same fixative at $4^{\circ} \mathrm{C}$ overnight and was then post-fixed with $1 \%$ osmium tetroxide and $0.05 \%$ potassium ferricyanide for $1 \mathrm{hr}$ at room temperature. The tannic acidtreated tissue (mouse 1) was best for viewing membrane densification, and the ferricyanide-treated tissue (mouse 2) was best for viewing the trilamellar unit membrane structures. Tissue was stained en bloc in 3\% uranyl acetate in $80 \%$ methanol, dehydrated with ethanol, and embedded in araldite. 


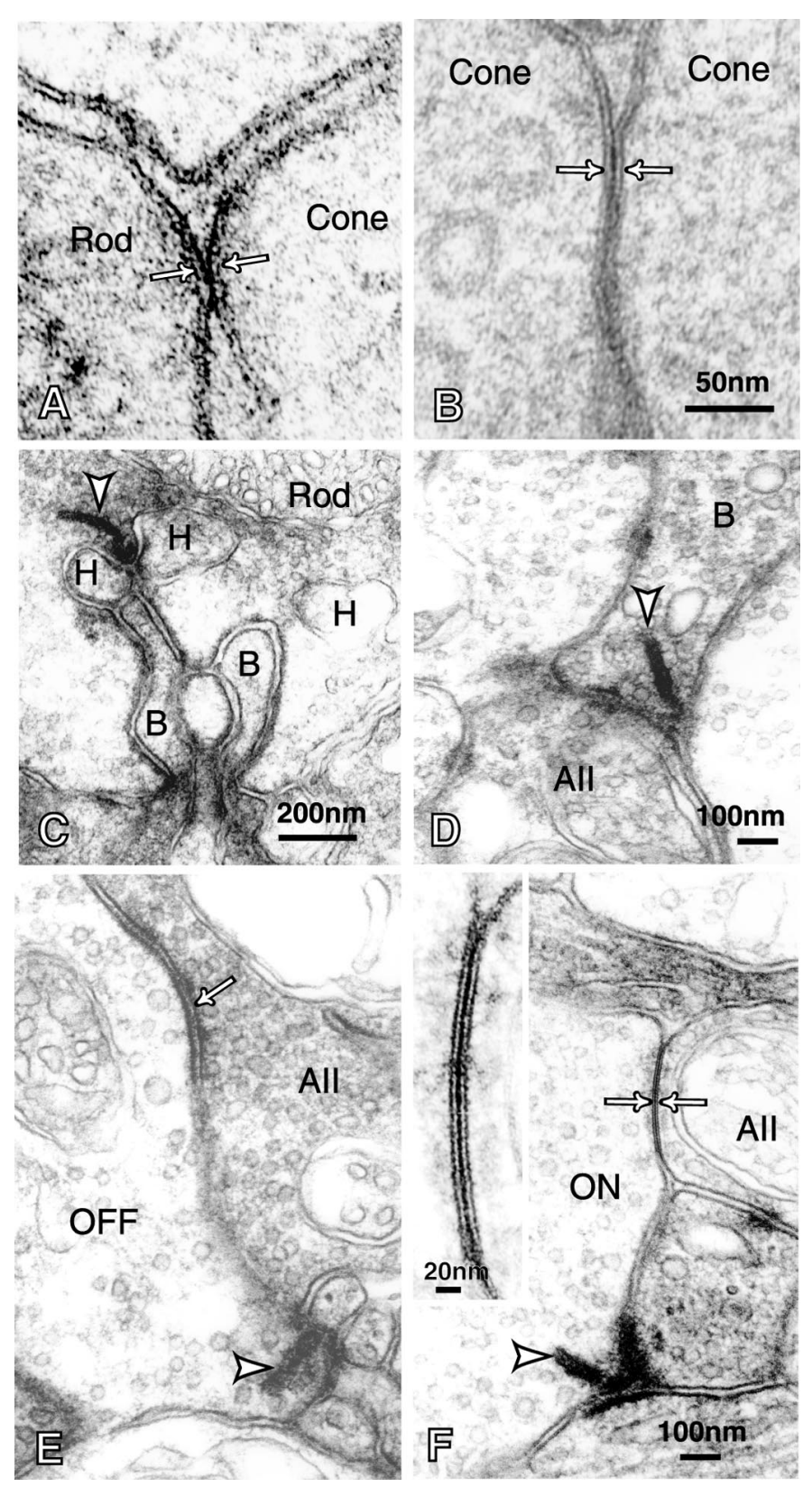

Figure 1. Mouse retina contains electrical and chemical synapses that serve two rod circuits known in other mammalian retinas. $A$, Rod-cone gap junction (arrows). B, Cone-cone gap junction (arrows). $C$, Two rod bipolar dendrites $(B)$ invaginating a rod synaptic terminal and extending close to the synaptic ribbon (arrowhead) that is flanked by horizontal cell processes $(H)$. $D$, Ribbon synapse (arrowhead) from rod bipolar axon to AII amacrine cell. E, Conventional chemical synapse (arrow) from the AII amacrine cell to an OFF cone bipolar axon terminal with ribbon output (arrowhead) to ganglion and amacrine cells. $F$, Large gap junction (arrows) between AII amacrine cell and ON cone bipolar axon terminal, shown at higher magnification in inset. Also, ribbon output (arrowhead) to ganglion and amacrine cells.

Serial reconstruction procedures. A series of 366 radial sections were cut from mouse 1 retina, and a series of 157 tangential sections were cut through the entire outer plexiform layer of mouse 2 retina, at the thickness of $90 \mathrm{~nm}$. Sections were mounted on Formvar-covered slot grids, stained with uranyl acetate and lead citrate, and photographed at $3000 \times$ (mouse 1 series) and 4000× (mouse 2 series) under a JEM1200EX electron microscope (JEOL, Tokyo, Japan). Certain synaptic contacts were rephotographed at $40,000 \times$ with various tilts. Three-

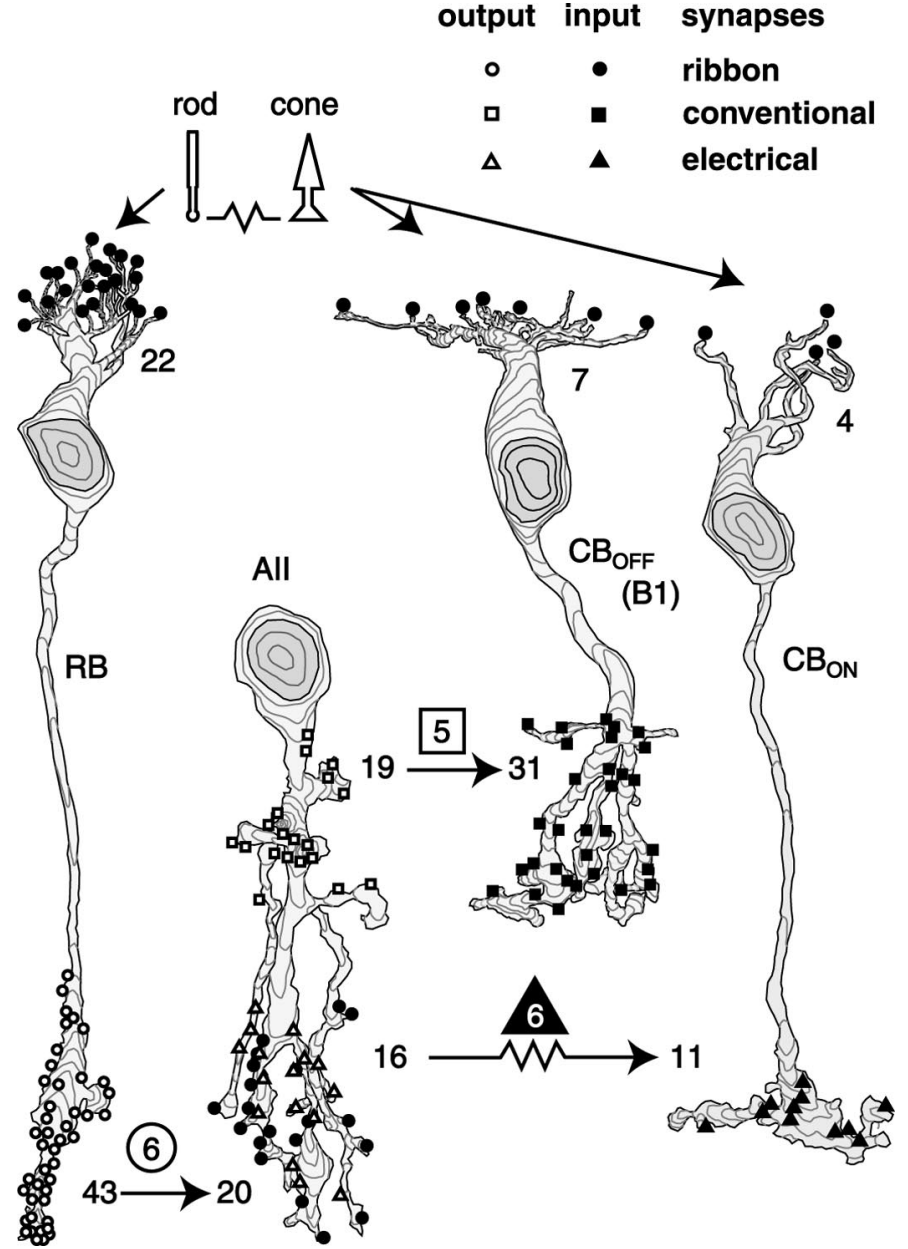

Figure 2. Mouse retina expresses two rod circuits known in other mammals. Reconstructions from electron micrographs of a single series approximately quantify the connections; each rod diverges to two rod bipolar cells, and 22 rods converge on one rod bipolar cell. The rod bipolar cell provides 43 ribbon synapses to AII amacrine cells. The AII forms 16 large gap junctions with $\mathrm{ON}$ cone bipolar terminals and 19 conventional synapses with the OFF cone bipolar terminals. The ON bipolar terminal receives 11 of these gap junctions, and the OFF bipolar terminal receives 31 conventional synapses. Numbers enclosed by a circle, square, and triangle represent the numbers of input or output synapses between a particular pair of adjacent cells. Total output synapses at the $\mathrm{ON}$ and OFF cone bipolar terminals are shown in Figure 3.

dimensional images were reconstructed with TRI graphic software (Ratoc, Tokyo, Japan) for Windows NT.

\section{RESULTS}

\section{Mouse retina expresses two standard rod pathways known in other mammals}

We first examined the gap junctions between photoreceptor terminals. Analyzing a series of tangential sections covering a small area of outer retina $(35 \times 45 \mu \mathrm{m})$, we distinguished two types of terminal. The rod terminal was small and contained a single ribbon synapse. The cone terminal was larger and contained many ribbon synapses $(10 \pm 1.6$ synapses; mean $\pm \mathrm{SD} ; n=20)$. We noted that each rod terminal always had gap junctions (Fig. $1 A$ ) with two processes ascending from cone terminals. At the base of a rod terminal, these gap junctions were usually opposite to each other across an opening for invaginating processes. These 

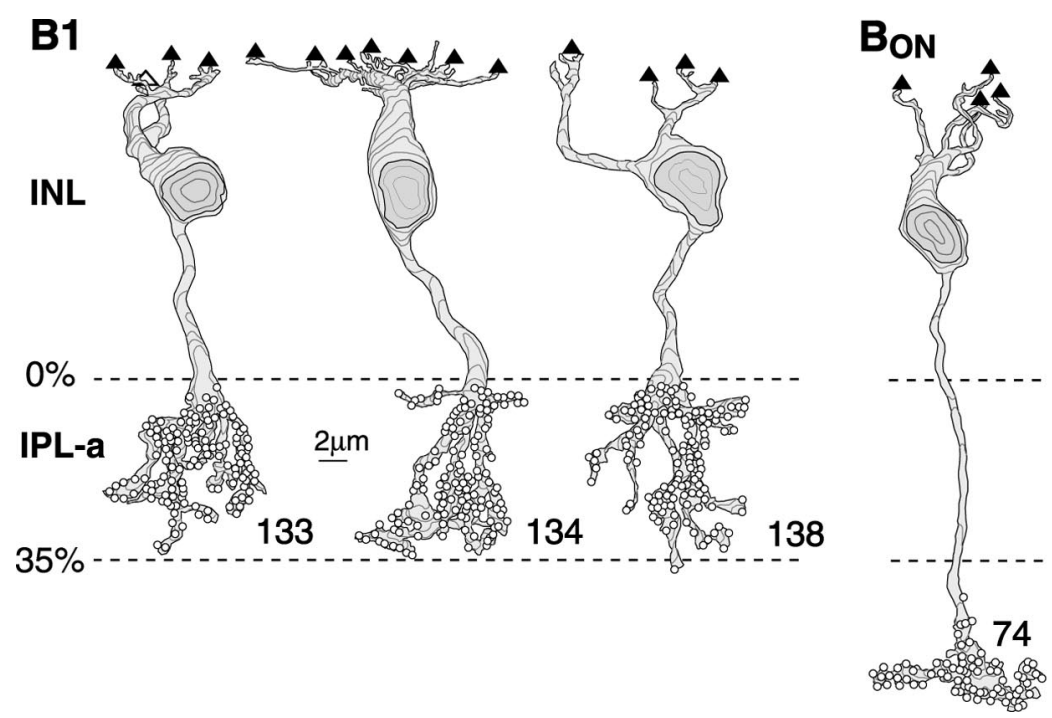

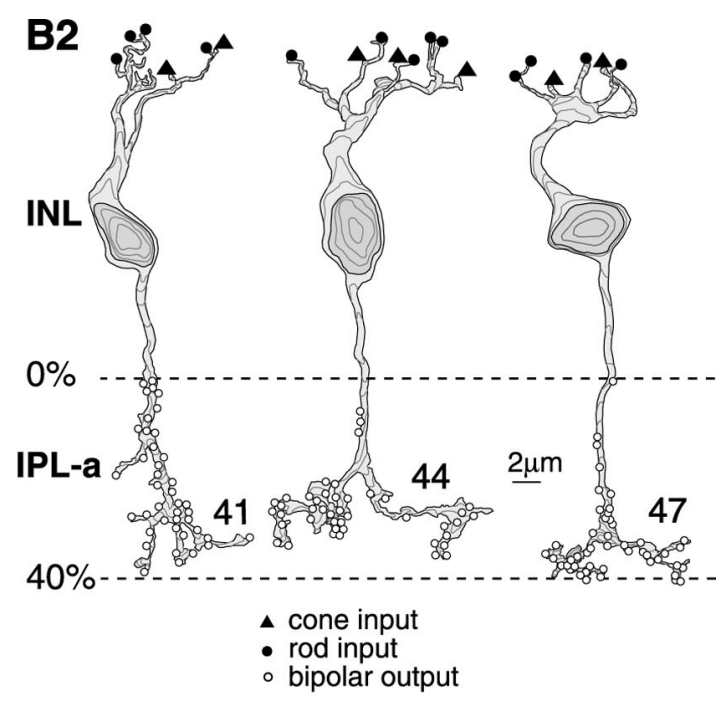

Figure 3. Two types of OFF cone bipolar cell and one ON cell identified by reconstruction. Type B1 is distinguished by a thick axon (1.0 $\mu \mathrm{m})$ and a large number of ribbon outputs that distribute throughout the OFF stratum. B1 receives direct contacts only from cones. Type B2 is distinguished by a thin axon $(0.6 \mu \mathrm{m})$ and modest number of ribbon outputs that distribute throughout the OFF stratum of the IPL. B2 receives direct contacts from both rods and cones. Type $B_{\text {on }}$ is distinguished by a thin axon $(0.75 \mu \mathrm{m})$ that provides a modest number of ribbon outputs in the ON stratum. It receives direct input only from cones. INL, Inner nuclear layer.

ascending processes mostly came from the same cone but occasionally from different adjacent cones. Cone terminals also protruded many tiny processes horizontally that formed cone-cone gap junctions (Fig. 1B). Thus, as in other mammals (DeVries and Baylor, 1995), cones couple to each other and (crucially for the "twilight" circuit) rods couple to cones.

Next, we used a series of vertical sections spanning a $90 \times 30$ $\mu \mathrm{m}$ patch of both plexiform layers to identify the synapses along the standard pathways. These synapses showed the same ultrastructure observed in other mammals: rod terminals were invaginated by rod bipolar dendrites (Fig. 1C), and the rod bipolar axon expressed ribbon synapses directed at the AII amacrine cell (Fig. 1D). The AII cell directed conventional chemical synapses at the axon terminals of OFF cone bipolar cells (Fig. 1E) (McGuire et al., 1984; Pourcho and Owczarzak, 1991; SassoèPognetto et al., 1994) and formed large gap junctions with axon terminals of $\mathrm{ON}$ cone bipolar cells (Fig. $1 F$ ). The axon terminals of OFF and ON bipolar cells formed many ribbon synapses onto amacrine processes and ganglion cell dendrites (Fig. 1E,F) (see Fig. 3).

We also surveyed the basic patterns of convergence and divergence along the rod and cone bipolar pathways (Fig. 2) by tracing the cells and synaptic connections through the available serial sections (Fig. 2). Many rods (22) converged on the rod bipolar cell, whereas few cones (four to seven) converged on the cone bipolar cells. The rod bipolar terminal expressed a modest number of ribbon synapses ( $43 \pm 1$; mean $\pm \mathrm{SD} ; n=3$ ) by which it diverged to multiple AII cells. The AII cell, collecting from several rod bipolar cells, expressed many electrical junctions (16) by which it diverged to several ON bipolar terminals. The AII cell also expressed many conventional synapses (19) by which it diverged to several OFF bipolar terminals of the same type. Additional detailed reconstructions will be needed to establish the definitive numbers of synapses and convergence-divergence; nevertheless, these numbers are comparable with those reported in cat (Sterling et al., 1988), rabbit (Strettoi et al., 1990), and monkey (Wässle et al., 1995).

\section{Two types of OFF bipolar cell}

We reconstructed six bipolar cells with axon terminals in the OFF strata of the inner plexiform layer (IPL) (Fig. 3). Three cells resembled each other: dendritic field spanning $\sim 10-18 \mu \mathrm{m}$, basal contacts from cones $(5 \pm 1.7$; mean \pm SD), stout axon $(\sim 1 \mu \mathrm{m}$ thick, measured $5 \mu \mathrm{m}$ below the soma), and a terminal arbor spanning $0-35 \%$ of the IPL. This elaborate arbor produced an enormous number of ribbon synapses $(135 \pm 3)$, each presynaptic to a pair of processes (dyad). The axon terminals of all three cells received chemical synapses from AII amacrine cells. These bipolar cells were separated by 10-15 $\mu \mathrm{m}$. The clustering by multiple parameters suggests that these cells belong to a specific type (Cohen and Sterling, 1990), here designated B1.

Three other bipolar neurons also resembled each other: dendritic field spanning $\sim 8-14 \mu \mathrm{m}$, standard basal contacts from approximately two cones, plus unusual, symmetrical contacts from approximately five rods (see below). The axon was thin $(\sim 0.6 \mu \mathrm{m})$, with a terminal arbor spanning $0-40 \%$ of the IPL. The number of ribbon synapses was quite modest $(44 \pm 3)$, including several in the axon stalk. Again, the clustering by multiple parameters suggests a specific type, here called B2. The dendritic arbors of two neighboring B2 cells were reconstructed from tangential sections (see Fig. 8). Averaging all five B2 cells (three in vertical sections and two in tangential sections), their dendrites received $2.2 \pm 0.4$ cones and $4.8 \pm 0.8$ rods. B2 bipolar cells were separated by $\sim 4-10 \mu \mathrm{m}$.

We fully reconstructed one ON bipolar cell and found its arbor to span levels $45-73 \%$ of the inner plexiform layer (Fig. 3). Because the convention of numbering bipolar cell types proceeds from outer to inner (Boycott and Wässle, 1991) and it is unclear how many types will be interposed between B2 and this ON cell, we designate it temporarily as $\mathrm{B}_{\text {on }}$. It resembles the rat type 7 cone bipolar cell (Euler and Wässle, 1995). 


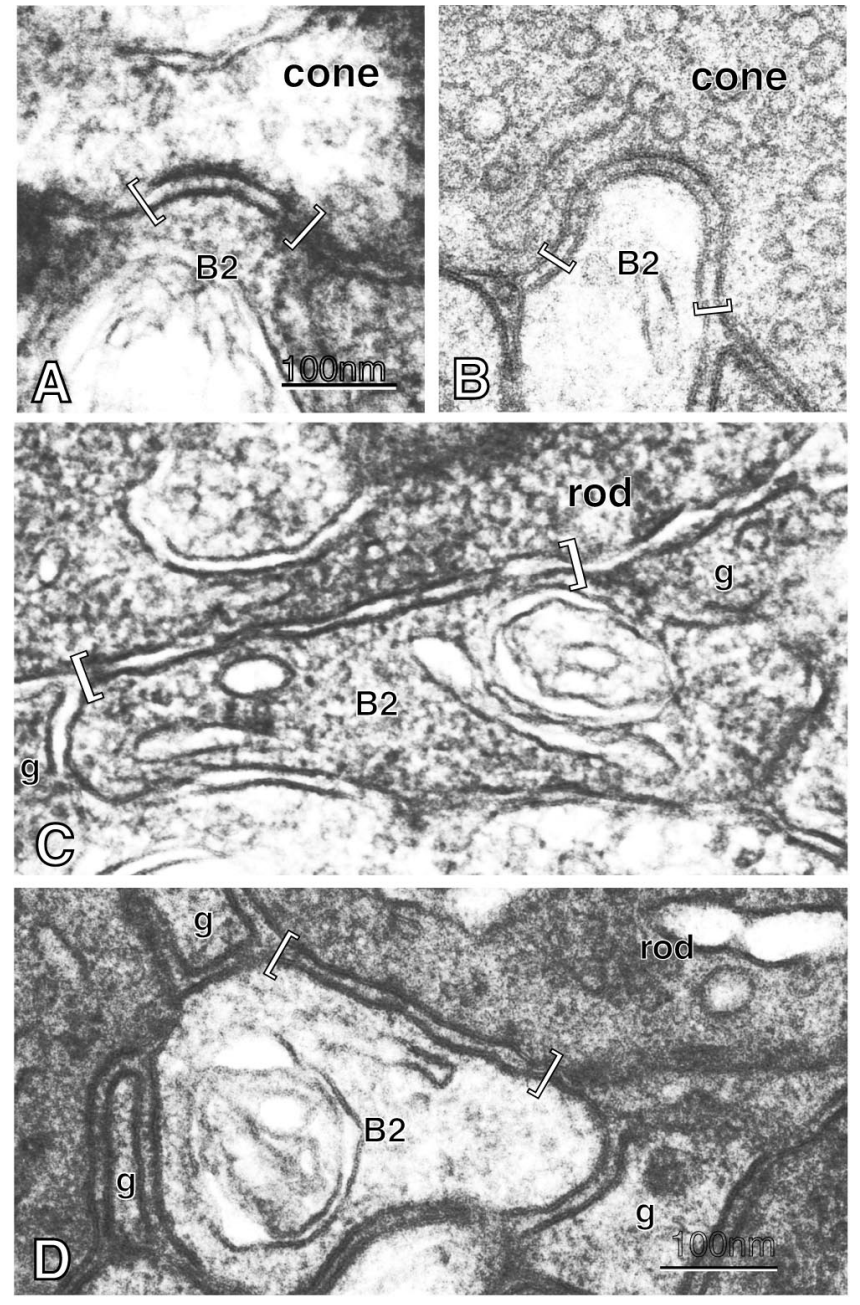

Figure 4. Ultrastructure of contacts between the B2 bipolar dendrites and cone and rod terminals. $A, B$, Cone terminals. Presynaptic and postsynaptic membranes are smooth and arched with a cleft of constant width $(\sim 20 \mathrm{~nm})$ that contains filamentous material. Presynaptic densification is evident, but postsynaptic densification is less prominent. $C, D$, Rod terminals. Glial wrappings $(g)$ make windows; contacts are large $\left(0.5-1.0 \mu \mathrm{m}^{2}\right)$ and rugged (brackets), and the clefts are variable in width $(15-25 \mathrm{~nm})$. Presynaptic and postsynaptic membranes are hardly densified, and filamentous material is seen at intermittent spots. $A$ and $C$ are from radial sections stained with tannic acid; $B$ and $D$ are from tangential sections stained with ferricyanide.

\section{Type B1 bipolar cell (but not type B2) collects synapses from the All amacrine cell}

All of the axons of three B1 cells shown in Figure 3 arborized among the lobular appendages of AII cells and received conventional, chemical synapses from the AII cells (Figs. 1E, 2). A particular B1 terminal received five such contacts from one AII cell and a total of 31 AII contacts (Fig. 2). Thus, the B1 cell is a key link for the standard rod bipolar pathway into the OFF system. The B2 axons also arborized among the AII lobular appendages. However, although we found five sites of membrane apposition (0.1-1 $\mu \mathrm{m}$ long) between two AII and two B2 cells, there were neither membrane specializations nor vesicle accumulations. Thus, the AII seems not to synapse on the B2 axon terminal. Whether there are more types of OFF cells that might connect with AII remains to be determined

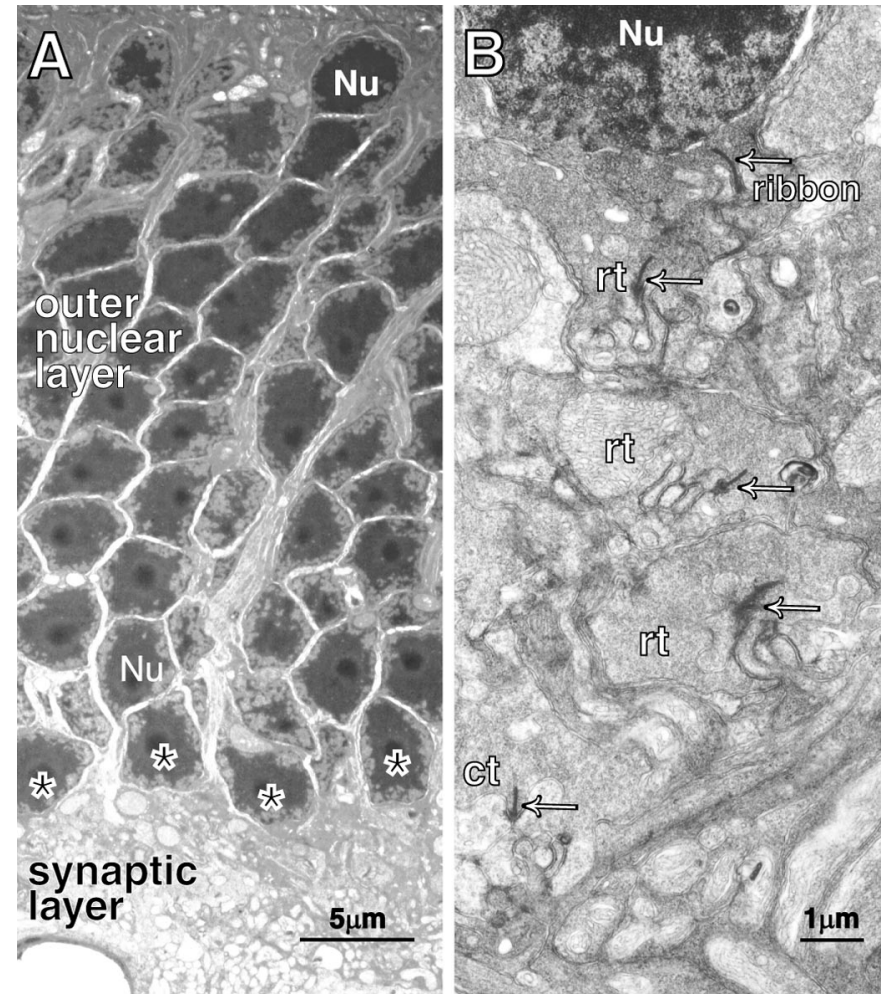

Figure 5. Photoreceptor somas and synaptic terminals stack in multiple tiers. $A$, Densely packed somas ( $\sim 96 \%$ rods) form $\sim 10$ tiers. $B$, Rod somas of the innermost somatic tier (* in $A$ ) form a ribbon synapse at the base (just beneath the cell nucleus). Rods and cones of the outer somatic tiers (as seen in $A$ ) form axons that snake between the somas to reach the outer synaptic layer, in which the terminals segregate. Cones plus some rods form the innermost synaptic tier; rod terminals form the outer synaptic tiers. $\mathrm{Nu}$, Nucleus; $r t$, rod terminal; $c t$, cone terminal.

\section{Mouse retina expresses a third rod pathway}

At the point at which a B2 dendrite contacted a cone terminal, there was a typical "basal contact" (Boycott and Kolb, 1973): the presynaptic membrane, devoid of docked vesicles, was indented by the dendritic tip; both presynaptic and postsynaptic membranes were densified; and the cleft had constant width $(20 \mathrm{~nm})$ and contained filamentous material (Fig. $4 A, B$ ). However, at the point at which the $\mathrm{B} 2$ dendrite contacted a rod terminal, the features were different: presynaptic membrane was not indented, but the area was substantial (up to $0.5 \times 1 \mu \mathrm{m}$ ), and the membranes displayed no consistent densification and varied in both cleft width and content of filamentous material (Fig. 4C,D). The rod-B2 contacts resembled those shown by Hack et al. (1999, 2001) to stain for iGluR subunits, and this led us to investigate whether all rods participate in this pathway.

The densely packed photoreceptor outer segments are narrow, whereas their somas and synaptic terminals are broad. Consequently, a monolayer of outer segments requires the somas to stack up, forming $\sim 10$ tiers (Fig. $5 A$ ). The underlying synaptic terminals must also stack, forming three to four tiers (Fig. $5 B$ ). Cone terminals form the innermost synaptic tier with a few intermingled rod terminals. The remaining rod terminals, each containing one ribbon, form the two to three outer synaptic tiers. Finally, the rod somas at the deepest somatic tier each contain a ribbon and active zone at the base of the soma itself (Fig. $5 B$ ).

The B2 dendrites reach the innermost tier of synaptic terminals, i.e., where cones and rods intermingle. The dendrites mostly 


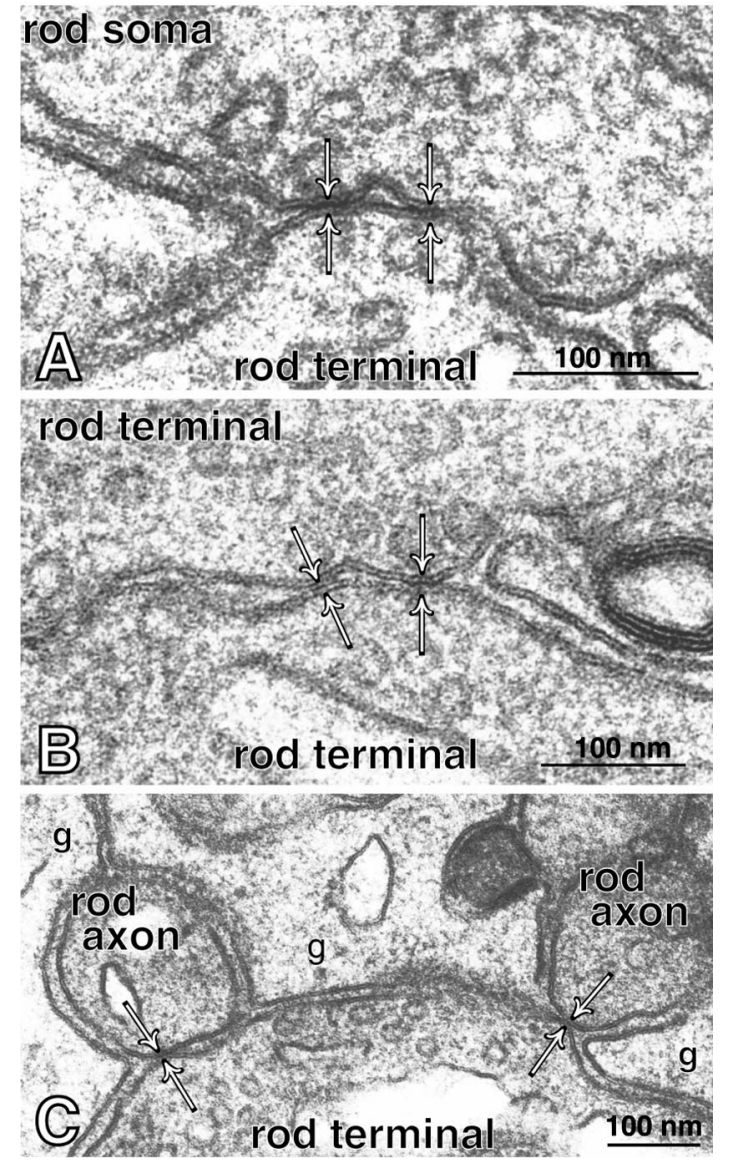

Figure 6. Rods contact each other via small gap junctions. $A-C$, Rod terminals contact the following: rod soma at innermost somatic tier $(A)$; another rod terminal $(B)$; and two descending rod axons wrapped by glial processes $(C, g)$. From tangential sections stained with ferricyanide.

stop there and barely penetrate the remaining tiers of rod terminals. Thus, B2 dendrites contact only a small fraction of all rods, $\sim 20 \%$. Wondering how the other rods might convey signals to the B2 dendrites, we searched carefully for evidence of rod-rod coupling, although it has generally not been observed in mammals (Smith et al., 1986).

We did find rod-rod gap junctions. These were small and convex, like a contact between two elbows (Fig. 6). They were present at several loci: between rod soma and rod terminal, between two rod terminals, and between rod terminal and passing rod axons (Fig. 6A-C). Although these contacts were not marked by adherent junctions [as between cones in primate retina (Tsukamoto et al., 1992)], they were marked by localized fenestration of the glial wrappings $(g)$ shown particularly well in Figure $6 C$. Furthermore, at the point at which two rods were coupled, they commonly formed junctions at several different sites.

We quantified the distribution of various photoreceptor gap junctions in serial sections cut tangentially through a region containing three cone terminals and 98 rod terminals (Fig. 7). Each cone formed one gap junction directly with the neighboring cone, but most of the fine processes emanating from the cone terminal connected to rods. Rod divergence to cones was minimal; each rod contacted only slightly more than one cone $(1.2 \pm$ 0.4 ), whereas convergence was considerable, $\sim 32 \pm 3$ rods contacted each cone. The ratio of convergence-divergence was 27.8, closely matching the ratio of the rod-cone densities $(334,000$

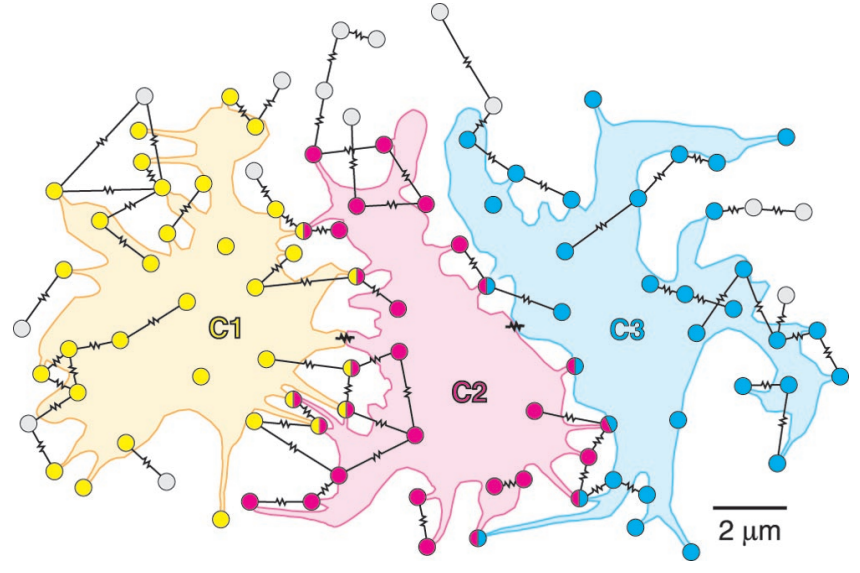

Figure 7. Reconstructed pattern of gap junctions; rods form local syncytia. Rod terminals (circles) that contact a given cone (C1-C3) via gap junctions are displayed in the same color as the cone (saturated for rod, pale for cone). A rod that contacts two cones is displayed in two colors. Cone-cone and rod-rod gap junctions are indicated by the symbol for ohmic resistance. Note that many rods converge on each cone, but each rod diverges very little. Most rods also couple to other rods, forming local syncytia of up to 11 rods. Only 12 rods of 98 were apparently isolated.

$\mathrm{mm}^{-2}$ rods/12,700 $\mathrm{mm}^{-2}$ cones was 26.3). This confirmed the accuracy of our connectivity measurements (Freed et al., 1987). Each rod contacted up to four neighboring rods (1.6 \pm 0.9$)$ (Fig. 7). Thus, a rod diverges more to rods than to cones.

\section{Three-dimensional reconstruction of synaptic input to B2 bipolar cells}

We reconstructed the contacts for two adjacent B2 cells using the same tangential sections as for the preceding gap junction analysis. The primary dendrites of the two cells were separated by $\sim 8$ $\mu \mathrm{m}$, and their dendritic arbors extended horizontally, producing fields $\sim 8 \mu \mathrm{m}$ in diameter with some overlap (Fig. $8 A$ ). One cell ( gray) collected chemical synaptic contacts from five rods (R1$\mathrm{R} 5)$ and two cones ( $\mathrm{C} 1$ and $\mathrm{C} 2$ ). The other cell (blue) collected from six rods (R6-R11) and two cones (C1 and $\mathrm{C} 2)$. Cones were shared, but the rods were not.

At higher magnification, we discerned a specific laminar arrangement of the connections (Fig. $8 B$ ). At the inner tier, the dendrites ( gray) contacted the basal surfaces of rod terminals (R2 and R3), plus the lateral and basal surfaces of R4. Terminals R12 and R13 lacked chemical synapses with the dendrites but coupled via gap junctions with R2. Similarly, terminal R14, located at the outermost tier, far from the dendrites, coupled to the R3 axon. Thus, signals from rods of the outer tiers can reach rods of the inner tiers and drive their chemical synapses with the B2 dendrites. Combining information from Figures 7 and 8 suggests that 25 rods converge onto one B2 cell (gray), and 21 rods converge onto the other (blue).

\section{DISCUSSION}

It is important to learn what circuit features are conserved between mouse and other mammals and how particular features change with scale and/or environmental niche. The first quantitative studies of mouse retina by light-electron microscopy showed that, despite the mouse's nocturnal reputation, cones and cone bipolar cells are quantitatively significant (Jeon et al., 1998). To this, Haverkamp and Wässle (2000) have added, by immunostaining, a major survey of retinal cell types and transmitter 



Figure 8. Three-dimensional reconstruction of synaptic input to two neighboring rod-cone OFF bipolar cells. $A$, Varicose dendrites of the bipolar cells are postsynaptic to five rods and two cones (B2-1 in gray) and to six rods and two cones (B2-2 in blue). B, Left side of $A$, rotated to show electrical pathways for rods that lack chemical synapses onto dendrites. The dendrites ( gray) receive chemical contacts (red patches) from rod terminals ( $R 2-R 4)$ in the innermost tier. One dendrite ascends to receive an extensive chemical contact (vertical red patch) along the lateral surface of $R 4$. Other rods (R12-R14) lack chemical synaptic contacts but make gap junctions (red resistance) with $R 2-R 4$. R13 is a rod soma (exceptionally protruding into the synaptic layer) with input to the dendrites (gray) via electrical junction with $R 2$. R15 does not connect to the dendrites.

receptors. The present study presents the first quantitative study of synaptic circuitry and offers several initial insights.

\section{Several circuits are conserved}

The basic circuits for "starlight" [rod $\rightarrow$ rod bipolar $\rightarrow$ AII amacrine $\rightarrow$ cone bipolar] and for "twilight" [ rod $\rightarrow$ cone $\rightarrow$ cone bipolar], previously identified in cat, rabbit, and primate (Dacheux and Raviola, 1986; Smith et al., 1986; Strettoi et al., 1990; Vaney et al., 1991; Wässle et al., 1995) are clearly evident in the mouse (Figs. 1, 2). Synaptic structures are also strongly conserved. Thus, the rod terminal in mouse has a single active zone and a synaptic ribbon with the same semilunar form as the rod terminal in cat and monkey (Rao-Mirotznik et al., 1995; Haverkamp et al., 2001). Because the length of active zone and size of ribbon are also conserved, they probably dock similar numbers of synaptic vesicles. This makes sense because the function of the rod synapse is also probably conserved: to transmit an irreducibly simple signal (binary), the arrival of 0 or 1 photon (Rao-Mirotznik et al., 1994). Even the rod bipolar terminal provides comparable numbers of active zones [mouse $\sim 43$ (Fig. 2) vs cat $\sim 30$; R. Rao-Mirotznik and P. Sterling, unpublished observations].

The cone circuits are also conserved in several respects. Cone terminals couple by gap junctions to neighboring cones and use both multiple ribbon synapses and multiple types of OFF bipolar cell. These features are thought to improve transmission of finely graded signals that cover a wide temporal bandwidth (DeVries, 2000; Freed, 2000). The numbers of ribbon synapses expressed by different types of mouse cone bipolar cell are also comparable with cat. The range in mouse (41-138 ribbons) (Fig. 3) is similar to cat (47-105 ribbons) (Cohen and Sterling, 1990).

\section{Some circuits are unique}

The mouse rod circuits exhibit certain features not found so far in larger mammals (Fig. 9). The innermost layer of rod terminals forms symmetrical contacts with dendrites of a rod-cone OFF bipolar cell (B2). Although these contacts lack obvious membrane specializations, they are probably not accidental: (1) reconstructions show the B2 OFF dendrites extending for several micrometers toward particular rod terminals (Fig. 3); (2) the glial wrappings around a rod terminal form a "window" to permit contact with the bipolar dendrite over a relatively wide area (Fig. $4 C, D$ ); and (3) membranes within this contact area are neither consistently dense nor constant in width, but these ultrastructural features are also seen at contacts between the rod and the processes immunostained for GluR1 and GluR2 (Hack et al., 1999, 2001). These receptor sites on the B2 OFF dendrites are rather far from the apex of the rod invagination, in which vesicles are released, but the distance is comparable with that from cone release sites to basal contacts (Calkins et al., 1996). We conclude that the rod $\rightarrow$ B2 bipolar junction, like a cone basal synapse, responds to an increase in glutamate concentration at light OFF by depolarizing the bipolar cell.

The only rod terminals to directly contact the B2 bipolar are those intermingled with the cone terminals in the innermost synaptic tier (Figs. $8 B, 9$ ). These amount to $\sim 20 \%$ of all rods in the B2 dendritic field. However, each rod diverges via gap junction (electrical synapse) to 1.6 other rods and thus forms local syncytia (Fig. 7). By pooling their signals with the rods that do form chemical synapses onto the B2 bipolar dendrites, most rods probably contribute to this fast OFF pathway. Rod-rod gap junctions have not been reported in larger mammals (monkey, 


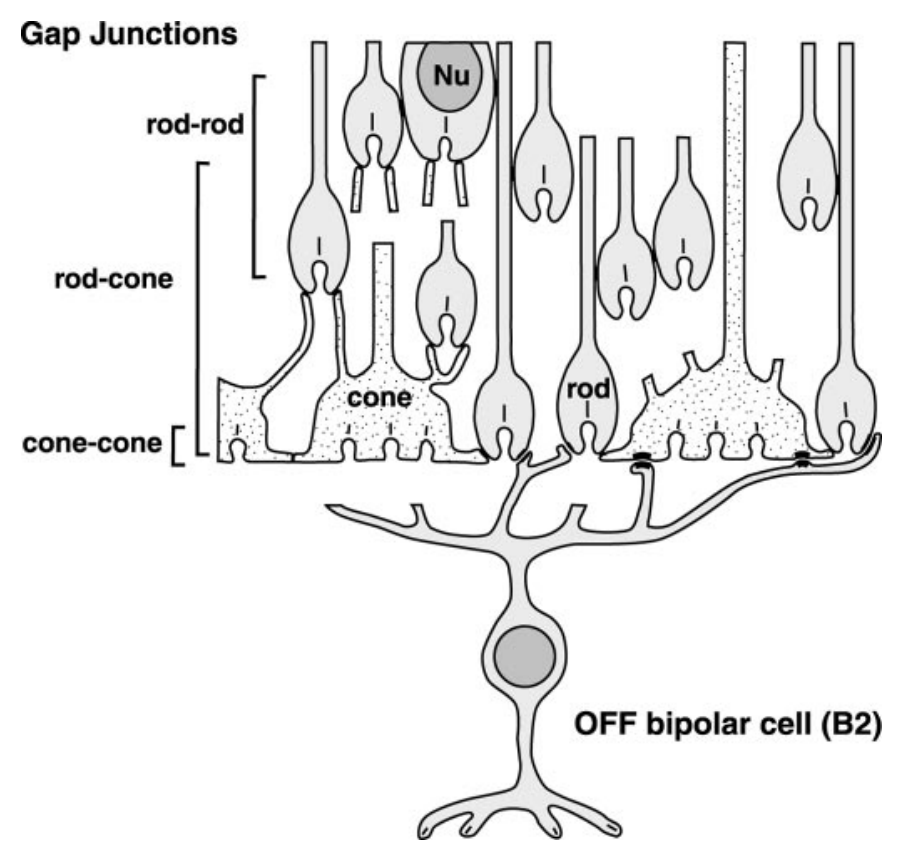

Figure 9. Circuit for fast rod pathway to OFF ganglion cell. Certain rods form symmetrical, iGluR-mediated synapses on dendrites of rod-cone OFF bipolar cells. Other rods lack direct access to these bipolar dendrites but couple electrically to the axons of rods that do have direct access. $\mathrm{Nu}$, Nucleus.

cat, and rabbit), but they are present in another small mammal, the guinea pig (P. Sterling, unpublished observation). This design, in which rods couple to each other, is well known in amphibians (Lasansky, 1972; Fain et al., 1976; Gold, 1979; Attwell and Wilson, 1980).

One can never be completely certain that gap junctions observed by electron microscopy are functional. However, the accumulated evidence that ultrastructural identification, such as illustrated in Figures 1 and 6, corresponds to a physiological conductance is extremely impressive. For example, the mammalian rod-cone gap junctions clearly conduct, because the rod signal is recorded directly in the cone (Nelson, 1977; Schneeweis and Schnapf, 1995). Furthermore, cone-cone coupling in mammalian retina has now been shown by dual patch-clamp recordings (S. H. DeVries, unpublished observations). In this context, the hypothesis seems reasonable that rod-rod gap junctions actually pool signals for conveyance via chemical synapses.

\section{Why are OFF pathways favored in mouse?}

Although much more remains to be learned about microcircuitry of mouse retina, what we know so far suggests that the OFF system is more highly developed than the ON system. Thus, the auxiliary rod pathway described here uses OFF but not ON bipolar cells. Also, the B1 bipolar axon, which carries the AII signal to OFF ganglion cells (Fig. 2), is more robust and expresses twofold more ribbon synapses than its ON counterpart (Fig. 3, compare $\left.B 1, B_{\text {on }}\right)$. With neither rod bipolar nor ON cone bipolar signaling, mGluR6-deficient mice showed almost the same performance for light-conditioned avoidance as the wild type (Masu et al., 1995). These mice relied on information carried solely in OFF pathways.

An OFF system will be more useful than an ON system in which background activity is strong enough that its suppression by an object darker than the mean level would give a good signal.
This implies that the auxiliary rod pathway ( $\operatorname{rod} \rightarrow$ B2 bipolar $\rightarrow$ ) would serve light levels in which there are many photoisomerizations $\left(R^{*}\right)$ per rod per integration time. At such levels, coupling pools rod signals and improves the signal-to-noise ratio, whereas with less than one $R^{*}$ per rod per integration time, coupling would pool rod noise and thus degrade the signal-to-noise ratio (Smith et al., 1986). In fact, the fast rod pathway identified physiologically by Soucy et al. (1998) in normal and coneless mouse, does operate over light levels that generate $\sim 5-500 R^{*}$ per rod per integration time. Why should this system be present in mouse and also possibly in guinea pig, rat (Muller et al., 1993), and gray squirrel (West, 1978)? Small rodents commonly spend considerable time in small, dark holes, looking out. At dawn and dusk, objects moving through their visual scene might tend to be faintly backlit and thus most efficiently detected by a rod-driven OFF system.

\section{REFERENCES}

Attwell D, Wilson M (1980) Behaviour of the rod network in the tiger salamander retina mediated by membrane properties of individual rods. J Physiol (Lond) 309:287-315.

Boycott B, Kolb H (1973) The connections between bipolar cells and photoreceptors in the retina of the domestic cat. J Comp Neurol 148:91-114.

Boycott B, Wässle H (1999) Parallel processing in the mammalian retina. Invest Ophthalmol Vis Sci 40:1313-1327.

Boycott BB, Wässle H (1991) Morphological classification of bipolar cells of the primate retina. Eur J Neurosci 3:1069-1088.

Calkins D, Tsukamoto Y, Sterling P (1996) Foveal cones form basal as well as invaginating contacts with diffuse ON bipolar cells. Vision Res 36:3373-3381.

Cohen E, Sterling P (1990) Demonstration of cell types among cone bipolar neurons of cat retina. Philos Trans R Soc Lond B Biol Sci 330:305-321.

Dacheux RF, Raviola E (1986) The rod pathway in the rabbit retina: a depolarizing bipolar and amacrine cell. J Neurosci 6:331-345.

DeVries SH (2000) Bipolar cells use kainate and AMPA receptors to filter visual information into separate channels. Neuron 28:847-856.

DeVries SH, Baylor DA (1995) An alternative pathway for signal flow from rod photoreceptors to ganglion cells in mammalian retina. Proc Natl Acad Sci USA 92:10658-10662.

Euler T, Wässle H (1995) Immunocytochemical identification of cone bipolar cells in the rat retina. J Comp Neurol 361:461-478.

Fain GL, Gold GH, Dowling JE (1976) Receptor coupling in the toad retina. Cold Spring Harb Symp Quant Biol 40:547-561.

Freed MA (2000) Parallel cone bipolar pathways to ganglion cell use different rates and amplitudes of quantal excitation. J Neurosci 20:3956-3963.

Freed MA, Smith RG, Sterling P (1987) Rod bipolar array in the cat retina: pattern of input from rods and GABA-accumulating amacrine cells. J Comp Neurol 266:445-455.

Gold GH (1979) Photoreceptor coupling in retina of the toad, Bufo marinus. II. Physiology. J Neurophysiol 42:311-328.

Hack I, Peichl L, Brandstätter JH (1999) An alternative pathway for rod signals in the rodent retina: rod photoreceptors, cone bipolar cells, and the localization of glutamate receptors. Proc Natl Acad Sci USA 96:14130-14135.

Hack I, Frech M, Dick O, Peichl L, Brandstätter JH (2001) Heterogeneous distribution of AMPA glutamate receptor subunits at the photoreceptor synapses of rodent retina. Eur J Neurosci 13:15-24.

Haverkamp S, Wässle H (2000) Immunocytochemical analysis of the mouse retina. J Comp Neurol 424:1-23.

Haverkamp S, Grünert U, Wässle H (2001) The synaptic architecture of AMPA receptors at the cone pedicle of the primate retina. J Neurosci 21:2488-2500.

Ishida AT, Stell WK, Lightfoot DO (1980) Rod and cone inputs to bipolar cells in goldfish retina. J Comp Neurol 191:315-335.

Jeon C-J, Strettoi E, Masland RH (1998) The major cell populations of the mouse retina. J Neurosci 18:8936-8946.

Kolb H (1977) The organization of the outer plexiform layer in the retina of the cat: electron microscopic observations. J Neurocytol 6:131-153.

Kolb H, Famiglietti EV (1974) Rod and cone pathways in the inner plexiform layer of cat retina. Science 186:47-49.

Lasansky A (1972) Cell junctions at the outer synaptic layer of the retina. Invest Ophthalmol Vis Sci 11:265-275.

Masu M, Iwakabe H, Tagawa Y, Miyoshi T, Yamashita M, Fukuda Y, Sasaki H, Hiroi K, Nakamura Y, Shigemoto R (1995) Specific deficit 
of the $\mathrm{ON}$ response in visual transmission by targeted disruption of the mGluR6 gene. Cell 80:757-765.

McGuire BA, Stevens JK, Sterling P (1984) Microcircuitry of bipolar cells in cat retina. J Neurosci 4:2920-2938.

Mills SL, Massey SC (1995) Differential properties of two gap junctional pathways made by AII amacrine cells. Nature 377:734-737.

Muller JK, Lukasiewicz PD, Silverman MS (1993) Rod and cone inputs to bipolar cells in the rat retina. Invest Ophthalmol Vis Sci 34[Suppl]:984.

Nelson R (1977) Cat cones have rod input: a comparison of the response properties of cones and horizontal cell bodies in the retina of the cat. J Comp Neurol 172:109-136.

Pourcho RG, Owczarzak MT (1991) Connectivity of glycine immunoreactive amacrine cells in the cat retina. J Comp Neurol 307:549-561.

Rao-Mirotznik R, Buchsbaum G, Sterling P (1994) Rate of quantal transmitter release at the mammalian rod synapse. Biophys J 67:57-63.

Rao-Mirotznik R, Harkins A, Buchsbaum G, Sterling P (1995) Mammalian rod terminal: architecture of a binary synapse. Neuron 14:561-569.

Sassoè-Pognetto M, Wässle H, Grünert U (1994) Glycinergic synapses in the rod pathway of the rat retina: cone bipolar cells express the alpha-1 subunit of the glycine receptor. J Neurosci 14:5131-5146.

Schneeweis DM, Schnapf JL (1995) Photovoltage of rods and cones in the macaque retina. Science 268:1053-1056.

Sharpe LT, Stockman A (1999) Rod pathway: the importance of seeing nothing. Trends Neurosci 22:497-504.

Smith RG, Freed MA, Sterling P (1986) Microcircuitry of the dark- adapted cat retina: functional architecture of the rod-cone network. J Neurosci 6:3505-3517.

Soucy E, Nirenberg S, Nathans J, Meister M (1998) A novel signaling pathway from rod photoreceptors to ganglion cells in mammalian retina. Neuron 21:481-493.

Stell WK, Ishida AT, Lightfoot DO (1977) Structural basis for On- and Off-center responses in retina of the goldfish. Science 198:1269-1271.

Sterling P (1998) Retina. In: The synaptic organization of the brain (Shepherd GM, ed), pp 205-253. New York: Oxford UP.

Sterling P, Freed MA, Smith RG (1988) Architecture of the rod and cone circuits to the On-beta ganglion cell. J Neurosci 8:623-642.

Strettoi E, Dacheux RF, Raviola E (1990) Synaptic connections of rod bipolar cells in the inner plexiform layer of the rabbit retina. J Comp Neurol 295:449-466.

Tsukamoto Y, Masarachia P, Schein SJ, Sterling P (1992) Gap junctions between the pedicles of macaque foveal cones. Vision Res 32:1809-1815.

Vaney DI, Young HM, Gynther IC (1991) The rod circuit in the rabbit retina. Vis Neurosci 7:141-154.

Wässle H, Grünert U, Chun M-H, Boycott BB (1995) The rod pathway of the macaque monkey retina: identification of AII-amacrine cells with antibodies against calretinin. J Comp Neurol 361:537-551.

West RW (1978) Bipolar and horizontal cells of the gray squirrel retina: Golgi morphology and receptor connections. Vision Res 18:129-136.

Young HM, Vaney DI (1991) Rod-signal interneurons in the rabbit retina. I. Rod bipolar cells. J Comp Neurol 310:139-153. 